The International Journal of Multimedia \& Its Applications (IJMA) Vol.8, No.6, December 2016

\title{
AN EXPLORATION OF THE CONCEPT OF TRANSMEDIA STORYTELLING IN THE UNITED STATES AND SOUTH KOREA: A SYSTEMATIC ANALYSIS
}

\author{
Young-Sung Kwon ${ }^{*}$ and Daniel H Byun $\dagger$ \\ *Department of Journalism and Mass Communications, Sungkyunkwan University, \\ Seoul, South Korea \\ $\dagger$ Department of Film, TV and Multimedia, Sungkyunkwan University, Seoul, South \\ Korea
}

\begin{abstract}
This research study sought to investigate how the concept of transmedia storytelling had been studied in both the United States and South Korea. The general objective of this research was to discover whether researches in the United States and South Korea studied the concept of transmedia storytelling differently and whether researchers in both the United States and South Korea have focused on different aspects of transmedia storytelling. Qualitative methods were used in the study. A systematic review was used as a method of data collection and analysis. The results of the study have revealed that the difference between studies that have been done in the United States and South Korea on the concept of transmedia storytelling have discernible differences. The only slight differences are with respect to the use of mobile technology and the scope and nature of the channels through which transmedia is experienced.
\end{abstract}

\section{KEYWORDS}

Transmedia, Transmedia Storytelling, Transmedia in Korea, Transmedia in the United States

\section{INTRODUCTION}

Transmedia storytelling is an evolving concept within the context of the communication and media industry. It was first propounded by Henry Jenkins, an American media scholar, who defined it as a process in which integral elements of a fiction are disseminated systematically across multiple media platforms with a view to achieving a unified and coordinated entertainment experience (Jenkins, 2007). According to Jenkins, every media channel is expected to make a distinct contribution to the unfolding of a fiction. In support of his idea of a transmedia storytelling process, Jenkins has given the example of The Matrix, a film story that has been unfolded through such multiple channels as live action films, collections of comic books, numerous video games and a series of animated shorts (Jenkins, 2007).

Even though the concept of transmedia storytelling is still evolving, it has already attracted the attention of many researchers in different field, especially where it has been applied. Some of the industries in which the concept has been applied and suited include entertainment and media, education, marketing and advertising industries. The studies have been done both within the United States, in which it originated, and outside the borders, especially in South Korea. Given the fact that the concept has been studied both within and outside the United States, it is possible that it has been studied differently; this means that the concept could be understood differently in various countries. Thus, the focus of this study was a comparison of how transmedia storytelling DOI : 10.5121/ijma.2016.8601 
The International Journal of Multimedia \& Its Applications (IJMA) Vol.8, No.6, December 2016

had been studied in both the United States and South Korea.

The study of the concept of transmedia storytelling was still evolving and many researchers were becoming interested in studying it. Given the fact that it had been studied in the United States and South Korea, it was important to understand how the concept had been studied in both countries. Unfortunately, no observable study had been done with this regard. The lack of such a study only meant that it would be impossible to understand how and whether transmedia storytelling is comprehended differently by researchers in both the United States and South Korea. Thus, this study was designed to undertake a systematic analysis of how the concept has been researched in both countries.

The general objective of the study was to study how the concept of transmedia storytelling had been researched in both the United States and South Korea. The specific objectives were:

1. To discover whether researches in the United States and South Korea studied the concept of transmedia storytelling differently

2. To find out whether researchers in both the United States and South Korea have focused on different aspects of transmedia storytelling

The following are the questions that the study sought to answer:

1. What are the differences in the ways in which researchers in the United States and South Korea have studied the concept of transmedia storytelling?

2. Have researchers in both the United States and South Korea studied the concept of transmedia storytelling by focusing on different aspects?

This study was justified on the ground that no study had been done to compare how the concept of transmedia storytelling had been studied in both the United States and South Korea. Therefore, it was significant in different ways, both practically and theoretically. Practically, the results of the study would provide insights into how researchers understood the concept of transmedia storytelling. Such insights would help in terms of shaping the direction of the study. In particular, the insights would provide feedback to scholars like Henry Jenkins, as to whether the definition of transmedia storytelling in South Korea is understood as was originally defined in the United States. On the theoretical grounds, the findings of the study added to the growing body of literature pertaining to research about the concept of transmedia storytelling.

\section{LITERATURE REVIEW}

\subsection{RESEARCH ON TRANSMEDIA STORYTELLING}

Formal research studies about transmedia storytelling commenced by the works of Henry Jenkins, who first coined the concept in the United States. In this regard, the origin of the concept is clearly the United States. Since then, the research has spread to other countries where it has been experimented in different industries. For instance, Scolari (2014) has described a situation of the about of the concept in Spain.

In his conclusion, Scolari (2014) has observed that transmedia productions in Spain were still at their nascent stages and, consequently, were limited. However, Scolari (2014) noted that the findings of a similar study that was done in Barcelona could be extrapolated to Spain as a whole. From the study, the scholar concluded that, even though related studies had been done in Barcelona, they were still incomparable to what had been done in the United States, but he 
The International Journal of Multimedia \& Its Applications (IJMA) Vol.8, No.6, December 2016

concluded that, in many cases, the works that are produced in Barcelona were mostly adaptations from the United States; this means that there is no difference between transmedia storytelling in the United States and Spain, specifically Barcelona, had no discernable differences. The implication of the foregoing exposition is that studies in Spain and the United States about transmedia storytelling would not yield any substantially different result.

According to an interview of a transmedia specialist that was conducted by Transmedia Storytelling Berlin (2012), the concept of transmedia storytelling in not yet a common subject in Portugal, meaning that it has not been applied as extensively as it has been used in the United States. Notably, the interview revealed that those who used the transmedia production strategy produced their products outside Portugal, then imported them into the country (Transmedia Storytelling Berlin [TMSB], 2012). Such a scenario is a testament that also studies on the concept are still scanty and may not be easy to conduct due to lack of effective transmedia experiences in the country.

In another relevant study, Gambarato and Alzamora (2012) were interested in establishing the status of transmedia storytelling in Brazil, with the focus being the evolution of media dynamics in the country and its future perspective. According to the researchers, the evolution of transmedia in Brazil had been influenced by theoretical and empirical events globally. With time, the media industry in the country gradually abandoned what the researchers have termed as the mono-mediatic perspective to adopt transmediality. However, it was notable that research about transmedia storytelling in the context of Brazil was still lacking. Importantly, Gambarato and Alzamora (2012) have observed that the concept of convergence of culture, which is very much associated with transmedia storytelling, had been witnessed in the context of Brazilian journalism. However, it is important to note that such an exposition does not reveal enough about how researchers in the country have studied transmedia storytelling.

\subsection{KNOWLEDGE GAP}

Evidently, not many studies had been done with regard to how the concept of transmedia storytelling has been studied in various countries. Importantly, in countries where such studies had been done, not enough knowledge had been generated. Notably, studies had been lacking with respect to how the concept had been studied in South Korea, compared to how it had been done in the United States. The various bodies of literature that had been tended to reveal that much of the research about transmedia storytelling has taken place in the United States, with only few ones having been done in other countries; this represented a knowledge gap that needed to be bridged.

\section{RESEARCH METHOD}

Since the subject of the study was relatively a new area and given the fact that not many studies had been done on it, a systematic review was preferred as the method of obtaining and analyzing data. A systematic review is a kind of a literature review that involves the collection and critical analysis of a multiplicity of studies or scholarly materials. The reason for the choice of a systematic review was that it would save time with respect to conducting a primary study, which would have posed a number of time-related and logistical challenges (Khan, Kunz, Kleijnen \& Antes, 2003).

\subsection{INCLUSION CRITERIA}

In order to conduct an appropriate systematic review, it was necessary to decide on the specific sources of information. In this respect, certain criteria were used, one of which was that the materials to be reviewed had be on the subject of research studies that had been done on 
The International Journal of Multimedia \& Its Applications (IJMA) Vol.8, No.6, December 2016

transmedia storytelling in either the United States or South Korea. Materials that did not concern the two countries were excluded from the study. In addition, the materials must have been produced in English and must have been produced by researchers. Finally, the materials to be reviewed had to contain qualitative data, because quantitative data were not intended for this study. The materials were obtained from various credible online databases, libraries and scholarly books.

\subsection{DAta COLlection AND ANALYSIS}

The systematic analysis process was conducted following five main steps as proposed by Khan, Kunz, Kleijnen and Antes (2003). In the first step, research questions were framed. The questions were replications of the study's research questions. In the second step, the relevant materials were identified, based on the research questions. The third step involved the evaluation of the qualities of the materials that were selected to ensure that the objectives of the study were achieved. The penultimate step involved the production of a summary of the evidence that was obtained from the materials. In the final stage, the findings that were obtained from the materials were interpreted according to how they answered research questions. The findings were then presented in a narrative form.

\section{RESULTS AND ANALYSIS}

\subsection{TranSMEDIA STORYTELLING IN THE UnITEDSTATES}

Transmedia storytelling is the work of Henry Jenkins. In Jenkins' definition, transmedia storytelling is representative of a process in which integral components of a fiction are disseminated methodically across multiple media networks with a view to creating an integrated and synchronized entertainment experience. According to Jenkins, each delivery network has a unique contribution to the unfolding of the story being told. The implication of Jenkins' definition of transmedia storytelling is that the different components of a fictional story are delivered to target audiences through different media outlets, so that an audience must go beyond just one media channel in order to obtain all the components of an unfolding story. Further, according to Jenkins (2007), transmedia stories are often based on intricate fictional worlds that can endure numerous interconnected characters and their stories.

The definition that has been offered by Jenkins implies that each part of an unfolding story is contingent upon other parts that unfold through different media. Therefore, it means that an audience cannot get the full experience of the whole story if he or she does not seek others elements as carried through other delivery channels. However, this definition has been criticized on the basis that not all audiences are interested in all the delivery channels and, as a result, those who do not access or search for other delivery channels may not get the experience of a whole story; this happens especially where there are no incentives for audiences to go beyond one delivery channel.

Importantly, different researchers seem to agree that Jenkins' definition does not take into account that, as a story unfolds through different delivery channels, the audience may not get the whole experience of the story because of inaccessibility of the channels of which they are not aware are in existence. The implication in this case is that audiences may only be aware of few delivery channels through which a story unfolds, thereby making it impossible to get remaining elements of the story.

While the definition of the concept of transmedia storytelling implies its application to fictional narrative only, Costa Sanchez (2014) has observed that its use has expanded to non-fictional contexts. For instance, Costa Sanchez (2014) has argued that both researchers and media 
The International Journal of Multimedia \& Its Applications (IJMA) Vol.8, No.6, December 2016

professionals have adopted the concept. In this regard, Costa Sanchez (2014) tends to expand on the definition that Jenkins offered by stating that the concept consists of a narrative structure that expands a story across different media, thereby providing multiple entry points and different reading levels to users. In his expanded definition, Costa Sanchez (2014) views transmedia storytelling as involving not just different media or delivery channels such as cinemas, televisions and video games, but also different languages, which, among others, can be verbal or iconic.

Since the advent of the concept of transmedia, researchers have increasingly focused on the distinction between the concept and cross-media. Notably, the confusion that arises between "transmedia" and "cross-media" is with regard the definition of the former. According to Jenkins (2011), who is the originator of the concept of transmedia storytelling, transmedia has a simple meaning of "cross-media," the level at which he contends that transmedia is a way of discoursing about the convergence of a conglomeration of cultural practices.

While making an observation on the concept, Scolari (2009) the conversations around transmedia storytelling also touches on such concepts as cross-media, enhanced storytelling and multiplatform, among others. In Scolari's (2009) view, these concepts amount to sematic chaos and they add to the complexity of the definition of the concept of transmedia. Scolari (2009) arrives at a definition that incorporates the observations of Costa Sanchez (2014) that transmedia storytelling involves both different languages and media. Based on the foregoing facts, Scolari (2009) concludes that transmedia storytelling is a narrative structure that expands through different media, such as cinemas and video games, and languages, such as verbal and iconic.

Taking into consideration the above definitions, it is evident that researchers in the United States view transmedia storytelling as not involving the process of adapting a story from one medium to another. In this regard, it is apparent that Jenkins and some researchers concur that transmedia storytelling is not about inter-semiotic translations or transfiguration from one system to another, but the dispersal of different components of a story through various media outlets and delivery channels. To prove this point, Jenkins (2007) has used The Matrix as a form of a story unfolding through different delivery networks. He explains that The Matrix is conveyed to audiences via three live action films, comic books and numerous video games. Another important example he has given is The "Wizard of Oz", a story that has unfolded through a series of music, cartoons and comic books. He uses The "Wizard of Oz" to demonstrate that transmedia storytelling existed long before he coined the term in 2003, but still proves his point.

However, it is important to note that, even though Jenkins contends that "transmedia" and "crossmedia" concepts can be defined similarly, other researchers have argued otherwise. For instance, Moloney (2014) has posited that the concept of "cross-media" has its roots in the advertising industry and that its meaning is the telling of a story through many different delivery channels. Up to this point, the definition tends to be similar to that of "transmedia." However, Moloney (2014) goes ahead to explain that, in cross-media, the same story and the same set of facts are repeated through the different delivery channels. It means that all delivery channels must capture any changes to an unfolding story;

In distinguishing transmedia from other related concept, Moloney (2014) provides what he believes should be the definitions. As to cross-media, the scholar states that there is only one story that unfolds through many media channels. With respect to multimedia, he advances the argument that there is one story in many forms, which unfolds through one delivery channel. When it comes to transmedia, he summarizes the definition to imply that there is one story world having many stories, which unfolds in many forms through multiple delivery channels. Evidently, these definitions are at variance with the conceptions that Jenkins has with respect to transmedia storytelling. Essentially, Moloney's (2014) arguments contradict the conception that the concept of transmedia can be defined as simply cross-media. 
The International Journal of Multimedia \& Its Applications (IJMA) Vol.8, No.6, December 2016

While contributing to the discourse about transmedia and cross-media, Costa Sanchez (2014) has explained that what makes the latter unique from the former is that cross-media approaches direct the public from one medium or delivery channel to another, primarily because of the need to deliver a complete message to audiences, which is not of any necessity in the context of transmedia. With this argument, Costa Sanchez (2014) implies that transmedia accounts are described by a sequence of distinct features that influence both the unfolding story and discourses about it.

Even though Jenkins' definition focuses on fictional stories, he has inconsistently observed that transmedia plays the role of reflecting the economics of media consolidation. According to him, given the fact that various media industries are horizontally integrated and that such industries have their interests across what were known to be distinctive industries. In support of this notion, Sutherland and Barker (2014) have observed that Jenkins' transmedia storytelling concept has been applied in the context of marketing communication, signaling the adoption of the concept in a real life, commercial contexts. This means that transmedia storytelling is not just about entertainment stories. In this respect, Sutherland and Barker (2014) have explained that industries can use transmedia storytelling to develop integrative narratives and communicate them across multiple delivery channels or platforms. The foregoing arguments elaborate the argument that has been made by Scolari (2009), stating that transmedia storytelling has been adopted in the area of brand management.

These arguments are evidence showing that the use of Transmedia storytelling as a concept has gone beyond the definition he provided, which only refers to a fictional story world. What this scenario signifies is that the scope of the transmedia storytelling has expanded to include real world stories such as information regarding product brands. Consequently, a new definition of the concept to cover what constitutes a non-fiction story world.

\subsection{Transmedia Storytelling In The CONTEXT OF SOUTH Korea}

Transmedia has developed significantly in South Korea, especially in the backdrop of technological developments in the field of communication. Kim and Hong (2012) have understood transmedia storytelling as the process in which multitudes of contents that are in synchronic subsistence are integrated into a larger entity, with a close link with the ubiquitous computing environment. According to Kim and Hong (2012), the computing environment exists courtesy of diverse media and platforms. In this respect, the two researchers have contended that the urban media realize a larger description through many distinct pieces of contents, which makes them comparable to the concept of transmedia storytelling. However, unlike Jenkins, Kim and Hong (2012) have not concerned themselves with issue of fiction, as it appears in Jenkins definition. Instead, their emphasis is on how communication technology in South Korea is supplementing the converging media that deliver different components of a story world.

Kim and Hong (2012) have further advanced the argument that transmedia storytelling utilizes a space-centered approach that provides an image of the contemporary tendencies of the storytelling. Importantly, they have posited that the key code of transmedia storytelling is what they term as the defamiliarization through the intricacies of unfolding stories. However, they fail to debunk the implication of such an argument. In contributing to the discourse, Jung (2016) views the concept of transmedia differently from the way Jenkins does. According to her, the fashion in which the image of a star, especially a singer, changes in an audience's mind amounts to a form of transmediation as it moves to actor from singer and to accessible from inaccessible.

According to Future Learn (n.d), two key features are essential for a proper comprehension of "transmedia storytelling" and "transmedia," which are textuality and multi-modality. Future Lean (n.d) has explained that radical textuality refers to situations in which several texts subsist within a singular medium, or when the structures of texts are more fluid in terms of organization as 
compared to texts in the past. As an example, Future Learn (n.d) states that a story is said to demonstrate radical textuality when a novel or movie can form several collaborative narratives that diverge according to the character or perception. Moreover, Future Learn (n.d) has further explained that when a story exhibiting radical textuality goes beyond its original medium of delivery and travels across media such as television series, games and films, it can be considered a transmedia story. The foregoing argument validates Jenkins explanation of what transmedia storytelling is.

Future Learn (n.d) has explained multi-modality as the utility that is displayed by distinct forms of media; this implies how each medium is best suited for a particular approach to storytelling, which influences the nature of content it can be used to disseminate. Future Learn (n.d) gives an example in which it states that narratives will often relay different kinds of messages and user experience when delivered through such formats as video games as against comic books. However, it makes the observation that, when originating transmedia storytelling, the influence that every medium that has been selected can possibly have on the whole world of the narrative is a noteworthy consideration for producers. Notably, the arguments by Future Learn (n.d) are in agreement with Jenkins' expositions about the concepts of transmedia and transmedia storytelling.

A number of studies on transmedia in the context of South Korea exist, although still scanty; Ok (quoted in Jenkins, 2009) has done one of the studies on what Jenkins (2009) has described as a groundbreaking research as to the deployment of transmedia practices in the Korean television. According to Ok, transmedia in Korea is defined by the ubiquitous mobile phones, which she describes as a new outlet for most media industries in the country. Accordingly, it means that it plays a significant role as one of the delivery channels through which a story can unfold within the meaning of Jenkins' transmedia storytelling. In conducting the study, Ok (quoted in Jenkins, 2009) used the "Click Click Ranger", alternatively known as Mobile Rangers, to demonstrate the influence of the concept of transmedia on Korea's media culture.

In "Click Click Ranger", which was aired on Channel MBC (Munhwa Broadcasting Corporation) in South Korea, the screens of mobile phones are used in two distinct ways. First, they are used as imaging for the production of moving images (quoted in Jenkins, 2009). Second, they are used as screens of mobile televisions for purposes of circulating images. In essence, the Ok views the mobile phone as performing many roles, one of which is a media outlet through which audiences can get parts of unfolding stories. In addition to the phone, the audiences can obtain the remaining parts of the story from other media, such as the television. In addition, according to Ok, the mobile phone has become a part of the covering media, which is one of the most important themes in Jenkins' Converging Culture (quoted in Jenkins, 2009).

Based on Ok's study, it seems that technology, especially regarding wireless communication, is an important element of transmedia storytelling in South Korea. The mobile technology defines how stories are dispersed through such other media as television, cinemas and videos, in the sense that they can be used to generate stories, for instance, through capturing moving images, and spreading them through other delivery channels to target audience; the target audiences also depend significantly on mobile phones as one of the delivery channels from which they have to get elements of stories that contribute to a given story world. Most importantly, even though Ok sought to use the "Click Click Rangers" to demonstrate the use of the concept of transmedia in South Korea, the study does not clearly bring out the element of transmedia storytelling as envisaged by Jenkins. For instance, Jenkins as given the example of the Matrix as a form of transmedia storytelling unfolding through different delivery channels such as video games, videos and cinemas. Instead, "Click Click Rangers" only makes of mobile phone as a form of generating and reeving components of unfolding stories. Ok has further failed to demonstrate how "Click Click Rangers" contribute to a specific story world. 
The International Journal of Multimedia \& Its Applications (IJMA) Vol.8, No.6, December 2016

Another study that has been with respect to the "Answer Me 1988". According to Jung (2016), the "Answer Me 1988" exemplifies the influence of transmedia in the South Korean entertainment industry, but in a perspective different from the one Jenkins contemplated in his definition. As a matter of recap, Jenkins' definition of transmedia storytelling advances the use of different delivery channels. However, in the case of "Answer Me 1988", Jung (2016) argues that even though its shows are through televisions, comic books, chat rooms and the internet, it utilizes transmedia in the form of spectators' nostalgia. Jung (2016) further explains that the convergence of different media takes place within the reasoning of individual consumers and through their public interactions with one another. Importantly, the researcher contends that contemporary viewers can utilize the show as a guide through the nostalgia different eras and cultures.

In furthering her argument, Jung (2016) has noted that "Answer Me 1988" has been expanded through different timelines; for example, there are series such as "Answer Me 1994", "Answer Me 1997" and other seventeen series that have been produced. According to the researcher, these series represent a process of trans-mediation or transmedia storytelling. In conclusion, the researcher as observed that the creator of "Answer Me 1988" gives viewers the transmedia experience through visual recollections across media channels; they experience every bit of it right through old music cassette tapes when they are visibly inserted into players, the faces that simply listen to the music and live concert shows on televisions that characters in the show watch as a group. What these arguments imply is that the "Answer Me 1988" show is a convergence of different delivery channels, such as audios, televisions and cinemas, through which components of a story world regarding different periods are delivered at once to viewers of the show. Evidently, even though these arguments apply the perspective of Jenkins on transmedia and transmedia storytelling, they have expanded the scope of the concepts to include social experiences and the use of shows containing different media channels as their elements; for instance, the "Answer Me 1988" show is projected in one screen, but within the show, there are other channels that casts are seen to be watching and listening to.

\section{CONCLUSION AND RECOMMENDATIONS}

\subsection{CONCLUSION}

Notably, studies about transmedia and transmedia storytelling in the United States and South Korea have revealed that there is no much difference. The only slight differences are with respect to the use of mobile technology and the scope and nature of the channels through which transmedia is experienced. For instance, while in both countries transmedia storytelling takes place through different distinct media outlets, in South Korea, studies have shown that a show like "Answer Me 1988" embodying a convergence of different media can still give the transmedia experience. In addition, research in South Korea has expanded the experience of transmedia to include the perceptions in the minds of viewers as to particular episodes within a show. For instance, the "Answer Me 1988" provided nostalgic experiences to viewers with respect to different events in the past, which Jung (2016) argues provide a transmedia experience. Given the foregoing arguments, it is evident that the meaning of transmedia storytelling needs a new definition.

Based on the findings of the study, it can be concluded that the study answered the research questions and achieved the objectives. With respect to the first question, the results of the study revealed that transmedia storytelling research in the United States and in South Korea did not have any difference, except with respect to the use of technologies, which was the focus of study with regard to transmedia in South Korea. In relation to the second question, the findings of the study did not reveal any possibility that researchers in South Korea focused on different aspects of transmedia storytelling from what their counterparts in the United States studied about the 
concept. Hence, the general conclusion is that the study of the concept of transmedia storytelling in both the United States and South Korea did not have much difference.

\subsection{RECOMMENDATIONS}

Generally, the study has revealed that the difference between studies that have been done in the United States and South Korea on the concept of transmedia storytelling have discernible differences. However, such studies are still very scanty. Hence, a number of recommendations are important. First, it is recommended that more studies should be done to determine whether there are differences between studies in the United States and other countries as to the concept. Second, future studies that will be focus on the current subject matter should focus on discovering how researchers in different countries understand and interpret transmedia storytelling as opposed to how they have studied it.

Importantly, because the findings of the study have made a significant contribution to the growing body of literature on how the concept has been studied, it is recommended that future researchers use the findings as a foundation for their research. In this case, the future researchers should utilize primary research methods in order to obtain most current information on the subject of study. It is noted that the studies that had been done with regard to the concept did not focus on the effects of national cultures on the understanding and application of transmedia storytelling in different countries. Accordingly, it is recommended that future studies should focus on such effects.

\section{ACKNOWLEDGEMENTS}

This paper was supported by Sungkyun Research Fund, Sungkyunkwan University, 2014.

\section{REFERENCES}

[1] Costa Sanchez, C. (2014). Transmedia storytelling, an ally of corporate communication: \#dropped by Heineken case study. Communication \& Society, 27(3), 127-150.

[2] FutureLearn. (n.d). Textuality and multi-modality. Retrieved from https://www.futurelearn.com/courses/transmedia-storytelling/1/steps/64122

[3] Gambarato, R., \& Alzamora, G. C. (2012). Transmedia Storytelling Initiatives in Brazilian Media. Medien Journal, $4, \quad 51-60 . \quad$ Retrieved from https://talkingobjects.files.wordpress.com/2012/01/gambarato_mj2012_4_bric.pdf

[4] Jenkins, H. (2007). Transmedia storytelling 101. Retrieved from http://henryjenkins.org/2007/03/transmedia_storytelling_101.html

[5] Jenkins, H. (2009). Click click ranger: A transmedia experiment for Korean television (part one). Retrieved from http://henryjenkins.org/2009/11/click_click_ranger_a_transmedi.html

[6] Jenkins, H. (2011). Transmedia 202: Further reflections. Retrieved from http://henryjenkins.org/2011/08/defining_transmedia_further_re.html

[7] Jung, G. (2016). Art cinema and media studies. Retrieved from https://aechjay.com/2016/05/13/answer-me-1988-응답하라-1988-a-transmedia-text-manual-tonavigate-another-eras-fandom/

[8] Khan, K. S., Kunz, R., Kleijnen, J., \& Antes, G. (2003). Five steps to conducting a systematic review. Journal of the Royal Society of Medicine, 96(3), 118-121. Retrieved from http://www.ncbi.nlm.nih.gov/pmc/articles/PMC539417/

[9] Kim, J., \& Hong, J. (2012). Analysis of trans-media storytelling strategies. Retrieved from http://onlinepresent.org/proceedings/vol12_2012/18.pdf

[10] Moloney, K. (2014). Multimedia, crossmedia, transmedia... what's in a name? Retrieved from https://ransmediajournalism.org/2014/04/21/multimedia-crossmedia-transmedia-whats-in-a-name/

[11] Scolari, C. A. (2014). Transmedia storytelling: New ways of communicating in the digital age. Retrieved

from 
The International Journal of Multimedia \& Its Applications (IJMA) Vol.8, No.6, December 2016

http://www.accioncultural.es/media/Default\%20Files/activ/2014/Adj/Anuario_ACE_2014/EN/6Storyte 1ling_CScolari.pdf

[12] Sutherland, K., \& Barker, R. (2014). The influence of transmedia storytelling portfolio examples on employer perceptions of public relations graduate employability - a pilot study. Asian Pacific Public Relations Journal, 15(1), 55-68.

[13]TMSB. (2012). Transmedia storytelling around the world: Nuno Bernardo. Retrieved from https://transmedia-storytelling-berlin.de/2012/04/transmedia-storytelling-around-the-world-nunobernardo/

\section{AUTHORS}

Young-Sung Kwon is Graduated from California State University majored in Radio/TV/Film, and received MA in Multimedia Communications. Currently a $\mathrm{PhD}$ candidate in the department of Journalism and Mass Communications at Sungkyunkwan University.

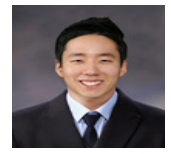

Daniel H. Byun Film Director. Received his PhD degree in Aesthetics from University of Paris 1. Currently an associate professor in the department of Film, TV and Multimedia at Sungkyunkwan University, Seoul. 